\title{
Pseudoexfoliative disease: histochemical evidence of an affinity with zonular fibres
}

\author{
A. GARNER AND R. A. ALEXANDER \\ From the Department of Pathology, Institute of Ophthalmology, University of London
}

SUMMARY The histochemical staining properties of the abnormal material deposited in the anterior segment of the eye in the pseudoexfoliation syndrome and the zonular ligaments of the lens are essentially the same. Both present the staining characteristics of oxytalan, the microfibrillar component of elastic tissue. Reasons are advanced for regarding the pseudoexfoliative material as a product of the ciliary and lenticular epithelium.

Despite having been a recognised entity for over 60 years the essential nature of pseudoexfoliative disease in the anterior segment of the eye is still obscure. ${ }^{2}$ This lack of understanding is reflected in the less than satisfactory names that have been given to it. Though it was initially regarded as an exfoliation of the lens capsule,, 2 comparison with the true exfoliation occurring as an occupational hazard in workers exposed to intense radiant heat, such as glass-blowers, led Dvorak-Theobald ${ }^{3}$ to question this assumption and introduce the term pseudoexfoliation. Indeed the first histological reports concerning the 'exfoliated' material by Busacca ${ }^{+}$had already given cause to doubt a lens capsule origin, and Gifford ${ }^{5}$ suggested a derivation from the zonular ligaments of the lens. It was hoped that the application of electron microscopy would supplement the limited information obtained from conventional light microscopy, and it has done so" "but without resolving the essential nature of the pseudoexfoliated material. Possibilities which currently command some support include amyloid formation, ${ }^{2}$ basement membrane exfoliation, "1 and zonule degeneration, ${ }^{5}$ but, as Dark and Streeten" observe, none has unequivocal substantiation.

The purpose of the present communication is to describe some histochemical findings which point to an affinity between the pseudoexfoliative material and the essential protein component of the lens zonules.

Correspondence to Professor A. Garner, 17-25 Cayton Strect, London ECIV 9AT.

\section{Material and methods}

Tissue from eight patients aged between 75 and 88 years, with pseudoexfoliatve disease diagnosed on the basis of histological examination at the Institute of Ophthalmology between 1980 and 1982, was subjected to a number of histochemical procedures concerned principally with the detection of elastic and related fibres. The specimens had previously been fixed in formol-saline and embedded in paraffin wax. Sections cut at $5 \mu \mathrm{m}$ were stained by the following techniques:

Verhocff's iron-hacmatoxylin to demonstrate mature clastic tissue Aldehyde-fuchsin to demonstrate clastic fibres.

Aldehyde-fuchsin after exposure to an oxidising agent (Caroat. the active principle of which is potassium peroxymonosulphate. supplied by Degussa Ltd. ( Cheadle Hulme. Cheshire) to identify the microfibrillar component of elastic. i.c., oxytalan.

Chrome hacmatoxylin modified to substitute Caroat as the oxidising agent in place of potassium permanganate advocated in Gomori's original method.

Gomori`s trichrome stain.

Combined alcian bluc/periodic acid Schiff sequence.

Congo red for amyloid.

Thioflavine $T$.

Hacmatoxylin and cosin

The complete anterior segment was present in five cases. In two lensectomy had previously been performed on account of cataract formation and in one the lens alone was available.

\section{Results}

The staining responses, recorded separately for the pseudoexfoliative material, the zonules and the lens capsules, are detailed in Table 1. 
Table 1 Histochemical staining responses for pseudoexfoliative material, zonules, and lens capsule

\begin{tabular}{|c|c|c|c|c|c|c|c|c|c|}
\hline Tissue & $\begin{array}{l}\text { Case } \\
\text { no. }\end{array}$ & $\begin{array}{l}\text { Verhoeff } \\
\text { elastic }\end{array}$ & $A F$ & $O x / A F$ & $\begin{array}{l}\text { Chrome } \\
\text { haem. }\end{array}$ & $\begin{array}{l}\text { Gomori } \\
\text { trichrome }\end{array}$ & $A B / P A S$ & Congo red & $\begin{array}{l}\text { Thioflavine } \\
T\end{array}$ \\
\hline Pscudo- & 1 & - & \pm & + & + & G & $\mathrm{AB}<\mathrm{PAS}$ & - & \pm \\
\hline exfoliative & 2 & - & - & + & + & G & $\mathrm{AB}<\mathrm{PAS}$ & - & \pm \\
\hline \multirow[t]{6}{*}{ material } & 3 & - & \pm & ++ & + & G & $\mathrm{AB}>\mathrm{PAS}$ & - & \pm \\
\hline & 4 & - & - & + & + & G & $\mathrm{AB}$ & - & \pm \\
\hline & 5 & - & - & + & + & G & $\mathrm{AB}<\mathrm{PAS}$ & - & \pm \\
\hline & 6 & - & - & + & + & G & $\mathrm{AB}<\mathrm{PAS}$ & - & \pm \\
\hline & 7 & - & \pm & ++ & + & G & $\mathrm{AB}<\mathrm{PAS}$ & - & \pm \\
\hline & 8 & - & \pm & ++ & + & G & $\mathrm{AB}<\mathrm{PAS}$ & - & \pm \\
\hline \multirow[t]{8}{*}{ Zonulc } & 1 & - & - & ++ & + & G & PAS & - & \pm \\
\hline & 2 & - & - & ++ & \pm & G & PAS & - & \pm \\
\hline & 3 & - & \pm & ++ & + & G & $\mathrm{AB}<\mathrm{PAS}$ & - & \pm \\
\hline & 4 & 0 & - & ++ & + & 0 & 0 & () & \pm \\
\hline & 5 & - & - & ++ & + & G & PAS & - & \pm \\
\hline & 6 & - & - & ++ & + & $\mathrm{G}$ & PAS & - & \pm \\
\hline & 7 & - & - & ++ & + & G & PAS & - & \pm \\
\hline & 8 & - & \pm & ++ & + & G & PAS & - & \pm \\
\hline Lens & 1 & 0 & 0 & 0 & 0) & 0 & ) & ) & 0 \\
\hline \multirow[t]{7}{*}{ capsule } & 2 & () & 0 & 0 & 0 & () & () & 0 & 0 \\
\hline & 3 & - & $+*$ & $+*$ & - & G & PAS & - & \pm \\
\hline & 4 & - & - & - & - & G & PAS & - & \pm \\
\hline & 5 & - & - & - & \pm & G & PAS & - & \pm \\
\hline & 6 & - & - & - & - & G & PAS & - & \pm \\
\hline & 7 & - & - & - & - & G & PAS & - & \pm \\
\hline & 8 & - & - & $+*$ & - & G & PAS & - & \pm \\
\hline
\end{tabular}

$\mathrm{AF}=$ aldehyde-fuchsin. $\mathrm{Ox}=$ oxidised section. $\mathrm{AB} / \mathrm{PAS}=$ combined alcian bluc/periodic acid Schiff. $\mathrm{G}=$ green. $0=$ not performed. ${ }^{*}$ Focal staining.

PSEUDOEXFOLIATIVE MATERIAL.

Pseudoexfoliative material was present by definition in all eight cases, though the amount and distribution varied somewhat. Always cellular and eosinophilic, the essential morphology was of tufts or clumps or delicate fibrils aligned perpendicularly to the surface to which they were attached, giving a characteristic 'carpet tuft' or 'hoar frost' appearance (Fig. 1).

The material did not react with Verhoeff's iron haematoxylin, but in four cases (cases 1, 3, 7, and 8) it

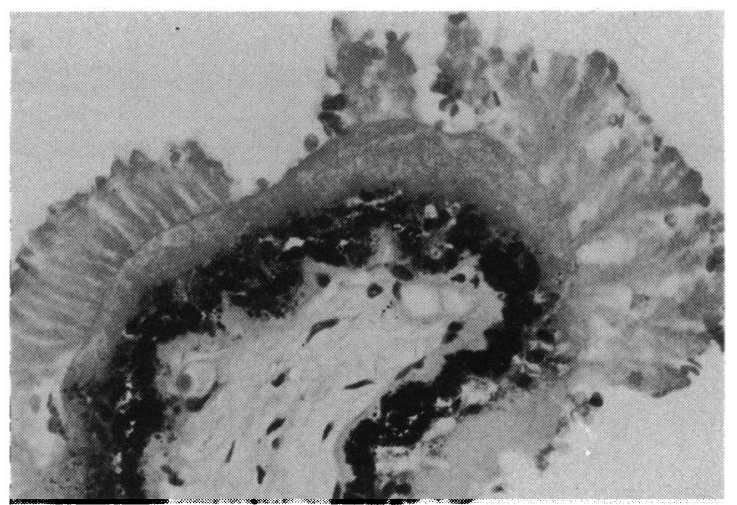

Fig. 1 Part of a ciliary process covered by tufts of pseudoexfoliative material. (Haematoxylin and eosin, $\times 245$ ). gave a weak reaction to aldehyde-fuchsin in nonoxidised sections. Prior oxidation by exposure to potassium peroxymonosulphate, however, resulted in the pseudoexfoliative material in every case reacting with aldehyde-fuchsin with marked enhancement in the cases which had otherwise given a weak response (Figs. 2-5). Chrome haematoxylin staining gave results similar to those with aldehyde-fuchsin on oxidised tissue, though generally less intense (Fig. 6). The Gomori trichrome stain produced a green

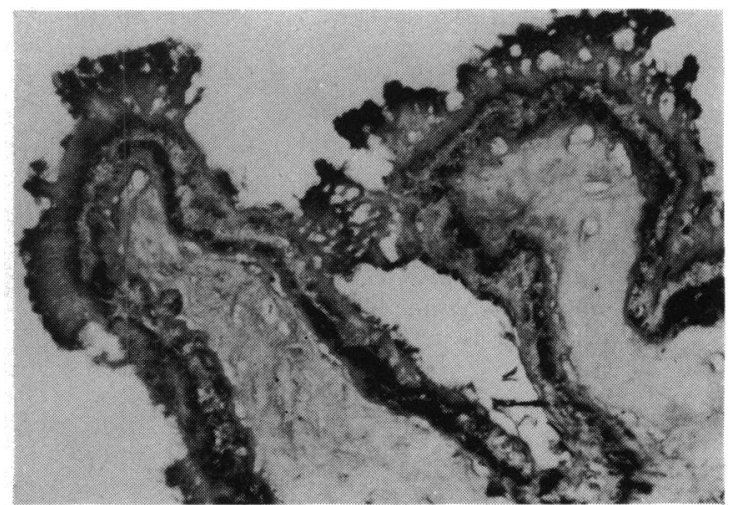

Fig. 2 The tufts of pseudoex foliative material on the ciliary processes are stained for elastic after oxidation of the section. (Oxidation, aldehyde-fuchsin, $\times 100$ ). 


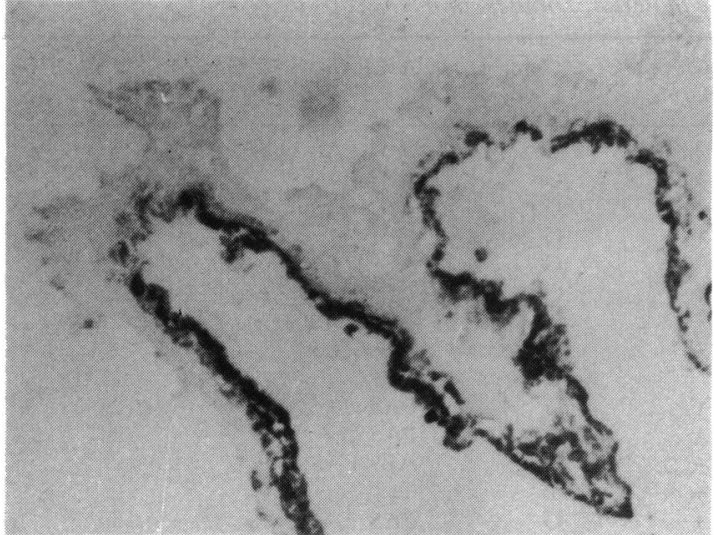

Fig. 3 Parallel section to that depicted in Fig. 2 shows no response to the elastic tissue stain in the absence of prior oxidation. (Aldehyde-fuchsin, $\times 100)$ ). colouration. In alcian blue/periodic acid Schiff stained sections the pseudoexfoliative material appeared to have two components, namely, a magenta-stained core with a coating of an alcianophilic substance. In two instances, however, where the deposits were relatively sparse and small (cases 3 and 4 ), the periodic acid Schiff positive component was inconspicuous. Congo red staining was essentially negative for amyloid in that the faint pinkish colouration frequently observed did not exhibit green dichroism by polarising microscopy. Thioflavine T stained sections examined by blue and by ultraviolet light showed weak fluorescence under the filters appropriate to amyloid detection.

\section{ZONULAR FIBRES}

The staining responses of the zonules were virtually identical to those recorded for the pseudoexfoliative
Fig. 4 Deposits on the anterior surface of the lens capsule stain for elastic after oxidation although the capsule is unstained. (Oxidation. aldehyde-fuchsin, $\times 170)$.
Fig. 5 Adjacent section showing negative staining for mature elastic tissue. (Aldehyde-fuchsin, $\times 170$ ).
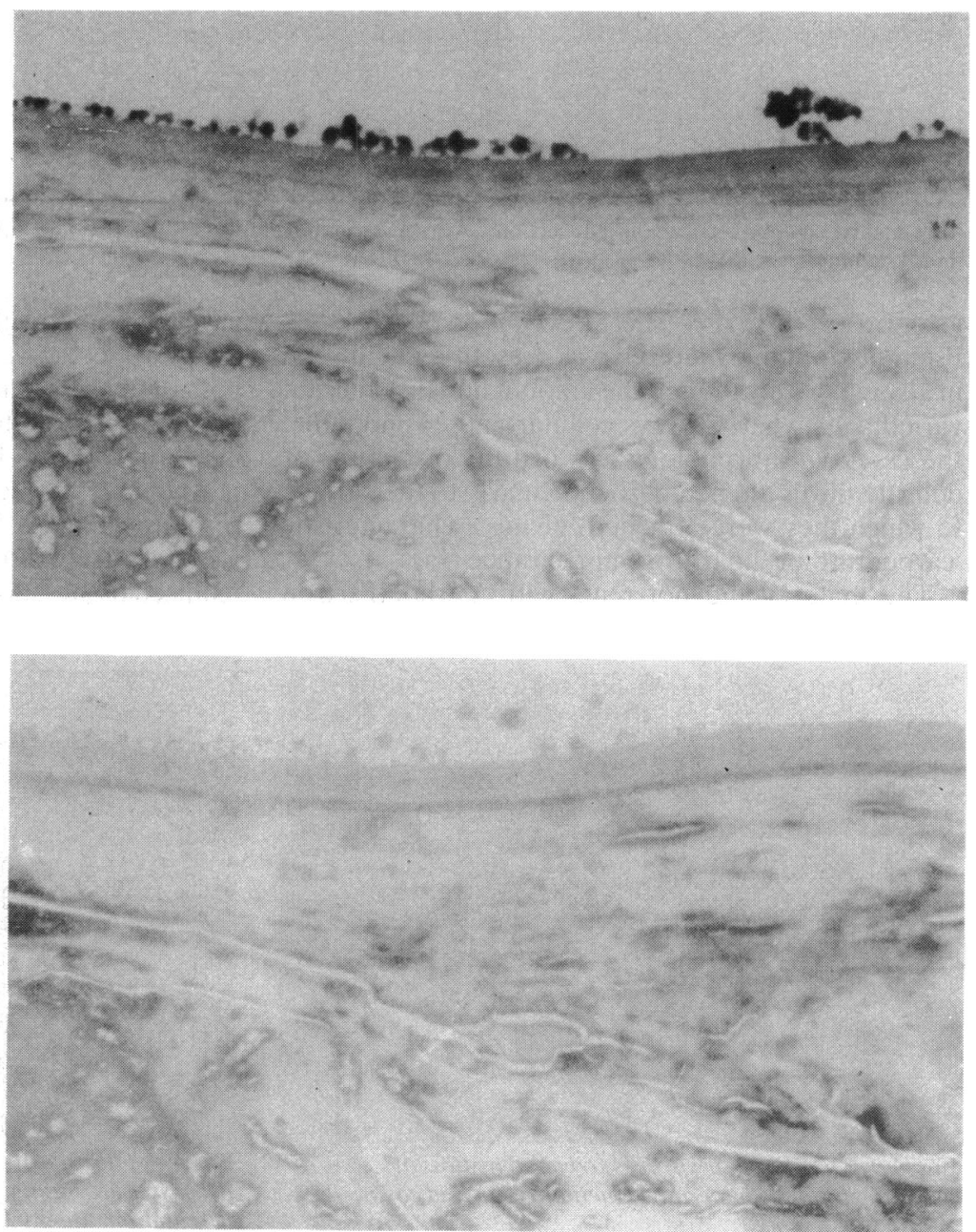
material. A weak reaction to aldehyde-fuchsin in the absence of preoxidation was observed in two cases (cases 3 and 8), but uniformly intense reactions were seen after oxidation in all cases. Except in case 3, in which a mixed response to alcian blue and periodic acid Schiff was seen, the zonular fibres did not take up the alcian blue stain. The reactions with amyloid stains were identical to those noted in respect of the pseudoexfoliative material.

\section{LENS CAPSUI.E}

Of the six cases in which lens tissue was present one (case 3) showed staining of the posterior part of the capsule with aldehyde-fuchsin that was not increased by preoxidation. Another, case 8 , gave a positive reaction to aldehyde fuchsin in the equatorial region after oxidation. In all other instances the response to this stain, with or without oxidation, was negative
(Figs. 4 and 5). Save for one instance (case 5), where weak response was obtained, the chrome haematoxylin method gave uniformly negative results. The capsules stained well with periodic acid Schiff but were not responsive to alcian blue and were stained green by Gomori's trichrome method. Negative reactions were obtained with Verhoeff's iron haematoxylin. and the responses to Congo red and thioflavine $\mathrm{T}$ corresponded to those given by the pseudoexfoliative material.

IRIS AND CIIIARY BODY

Deposits of pseudoexfoliative material were commonly found covering the pigment epithelium of the iris and sometimes formed a layer on its anterior surface (Figs. 7 and 8). Material staining with aldehyde-fuchsin after oxidation was also seen within the irideal stroma, particularly around blood vessels
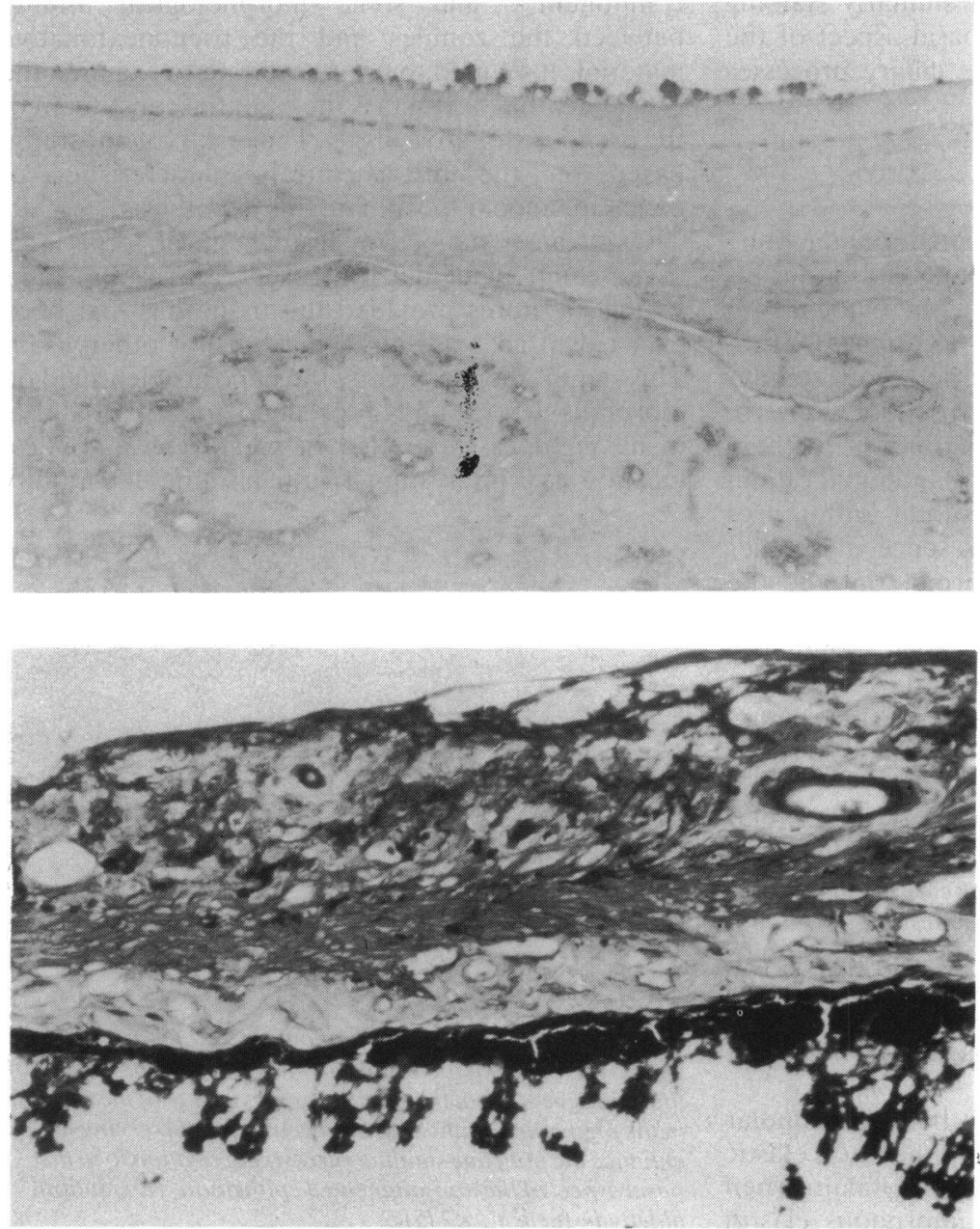

Fig. 6 Area comparable to that shown in Figs. 4 and 5 reveals staining of the pseudoexfoliative material by modified chrome haematoxylin. $(\times 170)$.

Fig. 7 The pigment epithelium and anterior surface of the iris are covered by deposits which stain for oxytalan. Some staining of the stroma anterior to the sphincter pupillae is also seen. (Oxidation, aldehyde-fuchsin, $\times 170$ ). 
Fig. 8 Comparable region of the iris showing negative staining for mature elastic tissue. (Aldehydefuchsin, $\times 170$ ).

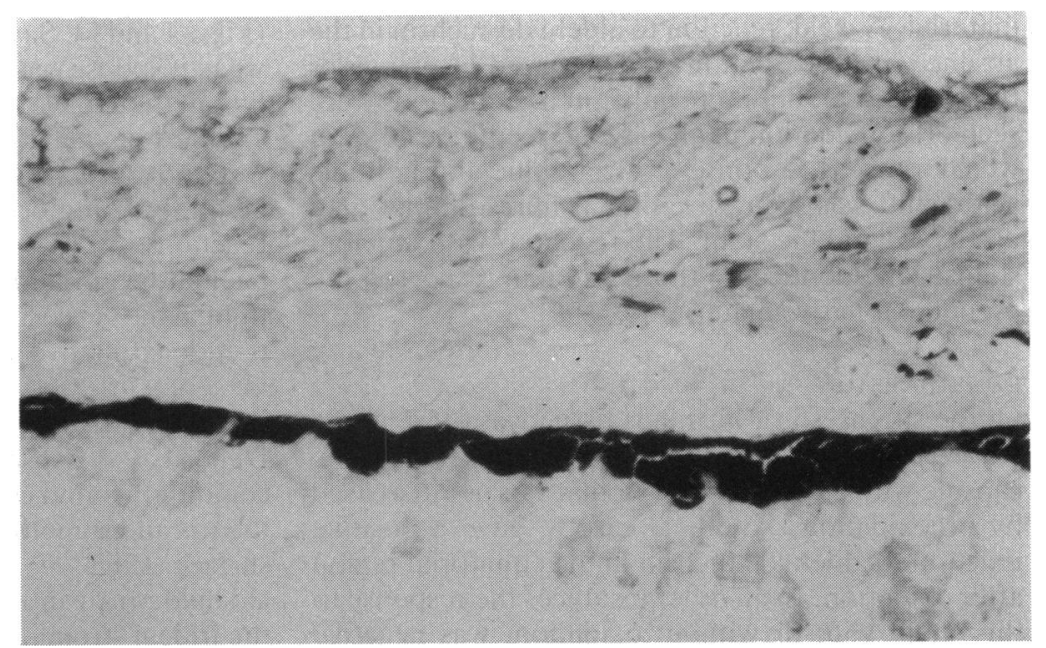

(Fig. 7). A spotty deposition of similarly staining material was prominent on the basal aspect of the non-pigmented epithelium of the ciliary processes (Fig. 9).

\section{Discussion}

The notion that pseudoexfoliative material might be similar in composition to the zonular fibres of the lens was first advanced by Gifford, ${ }^{5}$ but evidence to support this view has been slow to appear. Ultrastructural resemblance has been noted, both zonular fibrils ${ }^{1314}$ and the fibrils of pseudoexfoliative material ${ }^{(11)} 12$ consisting of microfibrils with a diameter of $8-10 \mathrm{~nm}$ and a cross-banding at $50 \mathrm{~nm}$ intervals. Even so there are subtle differences between them relating to the presence of smaller subunits in the pseudoexfoliative material and the need for special fixatives to demonstrate the banding of the zonular fibrils. " That morphological similarity does not necessarily imply identity is further emphasised by the observation that the ultrastructure of the pseudoexfoliative material has also been compared with that of amyloid. ${ }^{12}$

Other studies relating to the nature of the zonular fibrils which are rather more helpful in the context of pseudoexfoliative material composition are those showing biochemical, ${ }^{15}$ histochemical, ${ }^{16}$ and immunological ${ }^{17}$ comparability between the zonules and the tubular microfibrillar component of elastic tissue. These findings underscore the ultrastructural similarity between the two categories of fibril first noted by Raviola. ${ }^{13}$

In view of the close similarity between zonular fibrils and the microfibrillar component of elastic tissue, commonly referred to as oxytalan when occurring in isolation from the amorphous elastin component, ${ }^{1 \times}$ and some morphological affinity between the zonules and the pseudoexfoliative material, it seemed to us appropriate to examine the possibility that oxytalan is the essential constituent of the pseudoexfoliative fibrils. The results of our study, based on the histochemical characteristics of oxytalan, appear to validate this hypothesis.

Oxytalan is defined in histochemical terms as a for elastic fibres provided the tissue has first been exposed to an oxidising agent but not otherwise. ${ }^{\text {in }}$ This requirement is met by the deposits identified on morphological grounds as pseudoexfoliative material in all eight cases studied in whatever anatomical location. It is interesting to note also that the affinity

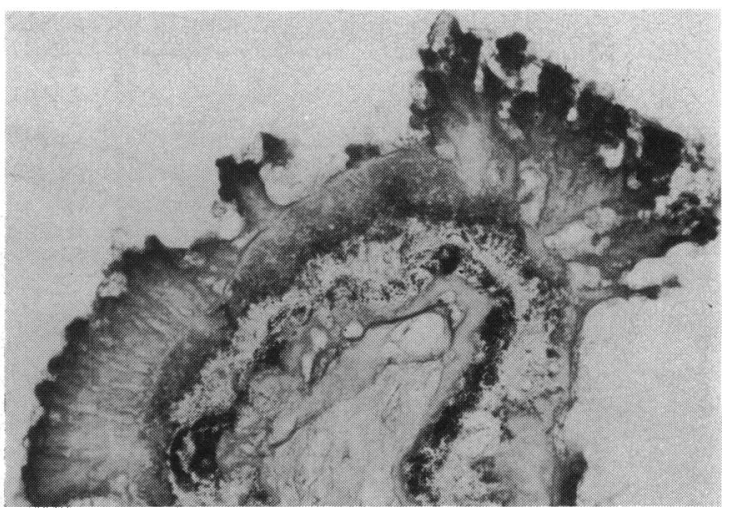

Fig. 9 Higher magnification of part of a ciliary process shown in Fig. 2 and for comparison with Fig. 1 . As a result of the oxidative stage in the staining process some of the melanin in the pigmented epithelium has been bleached serving to enhance the punctate staining (arrows) in relation to to the basal aspect of the non-pigmented epithelium. (Oxidation, aldehyde-fuchsin, $\times 245$ ). tissue component that will react with certain stains 
of the abnormal material for chrome haematoxylin noted by Dark and Streeten " and confirmed in the present study involves oxidation prior to staining.

The sole difference of note in our study between the two fibrils was that the pseudoexfoliative material was coated with an alcianophilic layer that was not seen in respect of the zonules. This could mean that the fibrils in pseudoexfoliative disease are "contaminated' with glycosaminoglycan, possibly to form a proteoglycan gel as proposed by Davanger." Alternatively the apparent absence of glycosaminoglycan in the zonules might be a fixation artefact, as Dark and Streeten "indicate, but, even so, as these authors also comment, it points to subtle differences between the zonules and pseudoexfoliative deposits. We could not detect any difference in fluorescence of thioflavine $T$ stained sections between lens capsule, zonules, and pseudoexfoliative fibres, which is in contradistinction to the preferential staining of the abnormal deposits reported by Dark and Streeten." The weak fluorescence we observed in each of these structures together with the absence of dichroism in Congo red stained sections argues against an amyloid composition for either zonules or pseudoexfoliative material.

Does knowing the nature of the pseudoexfoliative material enable us to comment on its source? With this question in mind it is relevant to observe that oxytalan as defined by both histochemistry and ultrastructure occurs in proximity to a variety of tissues. Originally it was described in the loose connective tissue surrounding tooth sockets, in tendons, ligaments, vascular adventitia, and dermis, ${ }^{21}$ and in the context of the eye it has been recognised in the cornea, ${ }^{21} \geq 2$ iris stroma, ${ }^{23}$ Bruch's membrane, and sclera $^{16}$ as well as the zonules. ${ }^{1+16}$ In some instances oxytalan fibres are a transient feature of the developing eye in the course of maturation to true elastic tissue, but in others, such as the cornea, its presence in adult life is always a manifestation of disease. Although the circumstances in which ocular oxytalan is seen vary widely, a feature common to several of the non-ocular conditions in which it develops is fluctuating mechanical stress. Thus it is prevalent in tooth sockets, tendons, and ligaments, while in the cornea it develops in situations such as post-traumatic scarring and keratoconus, where there is anatomical distortion. ${ }^{21}$ Furthermore, it is conceivable that the oxytalan manifested as pseudoexfoliative material could be the product of either lens or ciliary processes epithelium, these also being subject to variable mechanical stresses in accordance with the demands of accommodation. On the basis that the ciliary epithelium is the source of the oxytalan tissue of the normal zonular fibrils formed in utero it is not difficult to imagine that this capacity might be reawakened in later life if the appropriate stimulus was provided. The activation of a latent capacity on the part of the equatorial lens epithelium would explain the subcapsular accumulation of pseudoexfoliative oxytalan.

The finding of particulate material with the staining properties of oxytalan in relation to the basement membrane of the non-pigmented ciliary epithelium is in conformity with ultrastructural observations ${ }^{7112+4}$ and possibly lends some support to an epithelial origin, given that fibril assembly is essentially an extracellular event. Where oxytalan appears to be a product of cells which normally form a basement membrane, such as the corneal epithelium in keratoconus $^{21}$ and the corneal endothelium in Fuchs's dystrophy, ${ }^{22}$ the fibrils are deposited within or adjacent to the membrane. To this extent the evidence that pseudoexfoliative material is basically a preelastic moiety does not altogether contradict the suggestion first advanced by Trantas ${ }^{25}$ and most recently espoused by Eagle et al. ${ }^{10}$ that the pseudoexfoliation syndrome is a basement membrane disorder.

A true exfoliation of the zonules as proposed by Gifford ${ }^{5}$ seems unlikely, because on the one hand no clinical or histological evidence of zonule disintegration has been forthcoming, and on the other such an origin would not account for the observed presence of the abnormal deposits beneath the lens capsule and close to the basement membrane of the ciliary epithelium.

Until a consensus seems probable, it is perhaps advisable, as Dark and Streeten " suggest, to retain the term pseudoexfoliative disease. But, if our findings are accepted, some such term as oxytalanosis of the aqueous might find approval.

\section{References}

1 Lindberg JG. Thesis. Kliniska undersökningar över depigmentering av pupillarranden och genomlysbarhet av iris vid fall av alderstarr samt i normala ögon hos gamla personer. 1917: Hclsingfors: 1917

2 Vogt A. Ein neues Splatlampenbild des Pupillengebieties: Hellblauer Pupillensaufilz Häutchentildung auf der Linsenvorderkapscl. Klin Monatsbl Augenheilkd 1925; 75: 1-12.

3 Dvorak-Theobald G. Pseudo-exfoliation of the lens capsulc. Am J Ophthalmol 1954: 37: 1-12.

4 Busacea A. Struktur und Bedeutung der Häutchenniederschläge in der vorderen und hinteren Augenkammer. Albrecht von Graefes Arch Klin Ophthalmol 1927: 119: 135-75.

5 Gifford DH. A clinical and pathological study of exfoliation of the lens capsulc. Trans Am Ophthalmol Soc 1957; 55: 189-216.

6 Ashton N. Shakib M, Collyer R. Blach R. Electron microscopic study of pseudo-exfoliation of the lens capsule. I. Lens capsule and zonular fibers. Invest Ophthalmol Visual Sci 1965; 4: 141-53.

7 Shakib M, Ashton N, Blach R. Electron microscopic study of pseudo-exfoliation of the lens capsulc. II. Iris and ciliary body. Invest Ophthalmol Visual Sci 1965; 4: 154-61.

8 Bertelson TI, Drablos PA. Flood PR. The so-called senile exfoliation (pseudo-exfoliation) of the lens capsule, a product of lens epithelium. Acta Ophthalmol (Khh) 1964; 42: 1096-113. 
9 Dark AJ, Strecten BW, Jones D. Accumulation of fibrillar protein in aging lens capsulc. Arch Ophthalmol 1969; 82: 815-21.

10) Eagle RC. Font RL, Fine BS. The basement membranc exfoliation syndrome. Arch Ophthalmol 1979; 97: 51(1-5.

11 Dark AJ. Strecten BW. Pseudoexfoliation syndrome. In: Garner A, Klintworth GK, eds. Pathobiology of ocular disease. A dynamic approach. New York: Dekker. 1982: 1303-20.

12 Ringvold A. Husby G. Pscudocxfoliation material-an amyloidlike substance. Exp Eye Res 1973; 17: 289-99.

1.3 Raviola G. The fine structure of the ciliary zonule and ciliary epithelium: with special regard to the organization and insertion of the zonular fibrils. Invest Ophthalmol Visual Sci 1971; 10: $851-69$.

14 Strecten BW, Licari PA. The zonules and elastic microfibrillar system in the ciliary body. Invest Ophthalmol Visual Sci 1983; 24: $667-81$.

15 Strecten BW, Swann DA, Licari PA, et al. The protein composition of the ocular zonules. Invest Ophthalmol Visual Sci 1983; 24: $119-23$.

16 Alexander RA. Garner A. Elastic and precursor fibres in the normal human cyc. Exp Eye Res 1983; 36: 305-15.

17 Strecten BW. Licari PA, Marucci AA. Dougherty M. Immuno- histochemical comparison of ocular zonules and the microfibrils of elastic tissuc. Invest Ophthalmol Visual Sci 1981; 21: 130-5.

18 Fullmer HM, Lillic RD. The oxytalan fiber: a previously undescribed connective tissue fiber. J Histochem Cytochem 1958; 6: 425-30.

19 Davanger M. On the molecular composition and physicochemical propertics of the pscudoexfoliation material. Acta Ophthalmol (Khh) 1977: 55: 621-33.

20) Fullmer HM. Differential staining of connective tissue fibers in areas of stress. Science 1958; 127: 1240.

21 Alexander RA. Garner A. Oxytalan fibre formation in the cornca: a light and electron microscopical study. Histopathology 1977: 1: 189-99.

22 Alexander RA. Grierson I, Garner A. Oxytalan fibers in Fuchs' endothelial dystrophy. Arch Ophthalmol 1981; 99: 1622-7.

23 Noor Sunba MS, Rahi AHS, Garner A. Alexander RA, Morgan G. Tumours of the anterior uvea. III. Oxytalan fibres in the differential diagnosis of Ieiomyoma and malignant melanoma of the iris. BrJ Ophthalmol 1980); 64: 867-74.

24 Ghosh M, Speakman JS. The ciliary body in senile exfoliation of the lens. Can J Ophthalmol 1973; 8: 394-403.

25 Trantas M. Lésions séniles de la capsulc antéricure du cristallin et bord pupillaire. Arch Ophtalmol 1929; 46: 428-91. 